\title{
Presence and prevalence of UV related genetic mutations in uveal melanoma: similarities with cutaneous melanoma
}

\author{
A.Y. GOH ${ }^{1}$, C.A. RAMLOGAN-STEEL ${ }^{2, *}$, K. S. JENKINS ${ }^{3}$, J. C. STEEL ${ }^{2}$, C. J. LAYTON ${ }^{1,3, *}$ \\ ${ }^{1}$ University of Queensland, Faculty of Medicine, Brisbane, Australia; ${ }^{2}$ Central Queensland University, School of Health, Medical and Applied \\ Sciences, Rockhampton, Australia; ${ }^{3}$ LVF Ophthalmology Research Centre, Translational Research Institute, Brisbane, Australia
}

*Correspondence: c.ramlogan-steel@cqu.edu.au; c.layton@uq.edu.au

Received August 15, 2019 / Accepted October 2, 2019

\begin{abstract}
Ultraviolet (UV) radiation is an accepted etiological factor in cutaneous melanoma (CM), however its role in uveal melanoma (UM) is controversial. Partly as a consequence, CM and UM are often considered to be separate conditions, and advances in the treatment of CM have not led to joint clinical trials or parallel improvements in survival of UM. This study hypothesized that a subset of UM tumors displays evidence of genetic changes consistent with UV-related damage similar to that shown in CM. Analysis of the Broad Institute's Firebrowse depository of 80 UM samples and 343 CM samples, together with the Sanger Institute's Catalogue of Somatic Mutations in Cancer depository of 995 UM and 12,447 CM samples was undertaken to identify the most frequently mutated genes, mutation types, and specific nucleotide variants (SNVs) in each condition. Somatic mutation data were cross-correlated and shared mutations assessed against known effects of UV radiation. The proportion of samples with $\mathrm{C}>\mathrm{T}$ substitutions (a classic genetic marker of UV-related damage) was higher in UM than CM on both DNA strands ( $17.0 \%$ vs $13.1 \%, \mathrm{p}=0.038)$. The most frequently encountered cross-correlated mutated genes between UM and CM were, in order, BRAF, NRAS, TP53, CDKN2A, TERT, PTEN, ARID2, and KMT2C, with multiple common BRAF point mutations. Each cross-correlated mutation, and each common point mutation in BRAF, was associated with UV-related mechanistic changes. These findings support the hypothesis that the etiology of a substantial minority of UMs may be more UV dependent than previously recognized.
\end{abstract}

Key words: uveal melanoma, cutaneous melanoma, ultraviolet radiation

Cutaneous melanoma (CM) is the most common type of melanoma, accounting for more than $90 \%$ of melanomas worldwide. In comparison, the uveal tract gives rise to only $5 \%$ of melanomas, despite being the second most common site of origin. As a considerably more prevalent and studied disease, CM has largely guided, and continues to inform, the biological understanding and treatment principles of uveal melanoma (UM) [1].

Cutaneous and uveal melanocytes are derived from the common origin of neural crest melanoblasts. Clinically, the mainstay of treatment for both primary CM and UM is local excision, and the most important clinical prognostic factor is the size of the tumor, namely Breslow thickness and largest basal diameter, respectively. Both have high progression rates to metastatic melanoma, which once detected has an extremely poor prognosis and essentially resistant to standard chemotherapy [2]. As such, there is a significant demand for effective systemic therapies for both these malignancies, with numerous clinical trials currently underway, however many of these trials exclude UM as it is considered to have too many biological differences to $\mathrm{CM}[1,3]$. Arguably, one of the most significant of these differences is the etiological involvement of ultraviolet (UV) light.

The primary source of natural UV light is the sun, which emits UVA, UVB, and UVC - the latter of which does not penetrate the atmosphere. It is widely agreed that the UVB component of solar radiation is more carcinogenic than UVA, although UVA is more abundant than UVB, and like other genotoxic carcinogens, UV radiation causes DNA damage, which in turn, forms characteristic mutations in oncogenes and/or tumor suppressor genes, including a high frequency of cytosine to thymine (C>T) substitutions [4-6].

There are multiple photochemical mechanisms by which these mutations are formed, one of which involves the common UVB-induced formation of cyclobutane pyrimidines (CPDs) and 6,4 photoproducts. These photoproducts inhibit the DNA polymerase enzyme, arrest replication and if they remain unrepaired or are incorrectly repaired by DNA 
repair enzymes, they can induce mutagenesis through deamination and translesion DNA synthesis processes [7]. UVA, initially thought to be benign, is now increasingly implicated in skin cancer development, and exerts several biological effects. Through the formation of singlet oxygen, type I photosensitization and/or type II photo-oxidation reactions, UVA triggers oxidative changes to nucleotide bases. Guanine is particularly vulnerable due to its low ionization potential, transforming into 8-Oxo-7,8-dihydroguanine (8-oxo-G) and Fapy adducts that can ultimately lead to $\mathrm{G}>\mathrm{T}$ or $\mathrm{G}>\mathrm{A}$ mutations $[4-6,8,9]$.

There is a widely accepted association between CM incidence and UV exposure, particularly if intermittent and high-intensity (e.g. sunburns) or in childhood $[4,10]$. However, the mechanisms by which UV radiation triggers CM have not been fully elucidated, and are less understood than in non-melanoma skin cancers [8]. Complexities in the UV-CM relationship include tumor development in sites with little (e.g. acral) or virtually no sun exposure (e.g. mucosal), the lack of the typical UV signature in common CM driver genes (e.g. $B R A F)$, the impact of different patterns of UV exposure, and the influence of genetic, immunologic, and other factors (e.g. melanin types) [8, 11]. The effects of UV radiation on CM seem to vary according to the body site, the intensity of exposure, and additional factors that remain to be identified [8].

Nevertheless, UV radiation is the most well-established environmental factor in CM development. In contrast, there is controversy in the literature regarding its role in the pathogenesis of UM. Like CM, UM is associated with light iris color, fair complexion, dysplastic naevus syndrome (DNS), inherited differences such as the predominant melanin type formed in the individual and Caucasian race [12-15]. UM is also associated with the presence of atypical ocular naevi and other melanocytic disorders such as ocular and oculodermal melanocytosis [1, 16, 17]. These risk factors support the notion of a shared group of susceptible individuals between these two melanoma types.

From an anatomical perspective, uveal melanocytes are situated between the retinal pigment epithelium (RPE) and sclera, and are therefore not directly exposed to all wavelengths of incident light [13]. The most superficial layer through which UV light passes is the cornea, which absorbs wavelengths less than $295 \mathrm{~nm}$, but allows transmission of visible light, UVA, and most of the UVB spectrum $[18,19]$. The amount of UV light that reaches the uvea is dependent on multiple factors, including the angle of incidence of light, the absorption spectrum of different ocular media, and age of the patient, with more UV light reaching the posterior eye in childhood [20-22]. A positive correlation has been found between the distribution of UM tumors within the uveal tract and a solar radiation dosimetry map of the retinal sphere, which may suggest UM has a predilection for areas with the highest UV exposure (i.e. macula) [23].
There remains a significant controversy in the literature regarding the relationship between UV radiation and UM. However, the markedly higher incidence of UM in the Caucasian population together with epidemiological, geographical, and anatomical arguments raises suspicion in support of the hypothesis that ultraviolet (UV) radiation is a pathogenetic factor in its development. This study sought to characterize the mutation profile of CM and UM including their most frequent genetic alterations, mutation types, frequencies, and single nucleotide variants (SNVs) from very large groups of fully sequenced patient samples in order to elucidate whether the etiology of UM is similar to CM. It was hypothesized that $\mathrm{CM}$ and UM mutational signatures are comparable in terms of damage from UV light.

\section{Materials and methods}

COSMIC. All mutation data in the Sanger Institute's Catalogue of Somatic Mutations in Cancer (COSMIC) database (http://cancer.sanger.ac.uk/cosmic) [24] were manually sourced from peer-reviewed publications that reported large-scale genome screening data by COSMIC expert curators (Expert Curation Data), or imported from large-scale genome screening publications or other databases (e.g. ICGC) (Genome-wide Screen Data). The mutation screening methods employed and their sensitivities differ between each laboratory.

995 UM patient samples were obtained using the COSMIC Cancer Browser (http://cancer.sanger.ac.uk/cosmic/browse/ tissue), the following filters were applied to locate samples: 'Eye' under Tissue Selection > 'Uveal tract' under Subtissue selection > 'Malignant melanoma' under Histology selection > 'Include all' under subHistology selection. 12,447 CM patient samples were obtained with the following filters: 'Skin' under Tissue Selection > 'Include all' under Subtissue selection > 'Malignant melanoma' under Histology section $>$ 'Include all' under subHistology selection. Samples were analyzed to identify frequently mutated genes in UM and CM. Other somatic mutation data (e.g. frequency of mutations, mutation types (e.g. substitution, deletion, insertion) and specific SNVs were then collected for both types of melanoma.

GDAC Firebrowse. $80 \mathrm{UM}$ and $343 \mathrm{CM}$ patient samples with mutation data available were obtained from the uveal melanoma (UVM) and skin cutaneous melanoma (SKCM) cohorts in the Broad Institute GDAC Firebrowse database (http://firebrowse.org/). A MutSig v2.0 analysis was performed to determine the distribution of mutation types and mutational signature of the patient samples of both UM and CM cohorts $[25,26]$. A MutSig2CV v3.1 analysis was also performed to further characterize and compare the commonly mutated genes, their corresponding mutation rates and specific SNV s present between cohorts [27, 28]. Note that the nomenclature for SNVs (e.g. C>T) in the COSMIC analyses (e.g. C:G>T:A) differs from that of the GDAC 
Firebrowse analyses, where $\mathrm{C}>\mathrm{T}$ changes were not an isolated category, but rather a sum of the categories $\mathrm{CpG}>\mathrm{T}$ and $\mathrm{Cp}(\mathrm{A} / \mathrm{C} / \mathrm{T})>\mathrm{T}$ for the UVM cohort, and an unspecified proportion of the $(\mathrm{C} / \mathrm{T}) \mathrm{pC}>\mathrm{T}$ category in the SKCM cohort.

Statistical analyzes. Cloud based genetic descriptive statistics, comparisons, and crosscorrelation analyses were performed using embedded COSMIC and GDAC Firebrowse statistical tools to analyze data from each repository. IBM SPSS Statistics for Macintosh Version 21.0 was used to perform two-tailed Z tests to data between UM and CM. Statistical significance was defined as $\mathrm{p}<0.05$.

\section{Results}

Genetic landscape of UM and CM. A global view of the genetic landscape of UM $(n=80)$ and CM $(n=343)$ and their driver mutations was generated from GDAC Firebrowse data of their corresponding cohorts (Figure 1). No overlap of significantly mutated genes was observed, and a higher mutation load was detected in CM.

Distribution of mutation types and single nucleotide variants in COSMIC. Examination of the somatic mutations from the COSMIC database indicated that all $(\mathrm{n}=995)$ of the UM samples and a majority (99.6\%) of CM samples $(n=12,401$ of 12,447$)$ contained at least one genetic mutation. The spectrum of molecular subtypes of mutations and SNVs in COSMIC UM and CM samples was initially compared by assessing pie charts generated by inbuilt bioinformatics analyses to capture mutation types and SNV types. A comprehensive analysis of mutation types, including substitution nonsense, substitution missense, substitution synonymous, insertion inframe, insertion frameshift, deletion inframe, deletion frameshift, complex and others were performed. A similar distribution of mutation types and their corresponding frequencies were observed in UM and CM (Figure 2). The most frequent mutation type, present in the majority of UM and CM samples $(82.7 \%$ and $80.0 \%$, respectively) was substitution missense (Figure 2). $577 \mathrm{UM}$ and 7,155 CM samples demonstrated SNVs. The mutational signatures of SNVs in UM and CM were similar (Figure 3). The most common SNV was T:A $>\mathrm{A}: \mathrm{T}$ transitions, present in $48.0 \%$ and $50.2 \%$ of $\mathrm{UM}$ and CM, respectively ( $\mathrm{p}>0.05$ ).
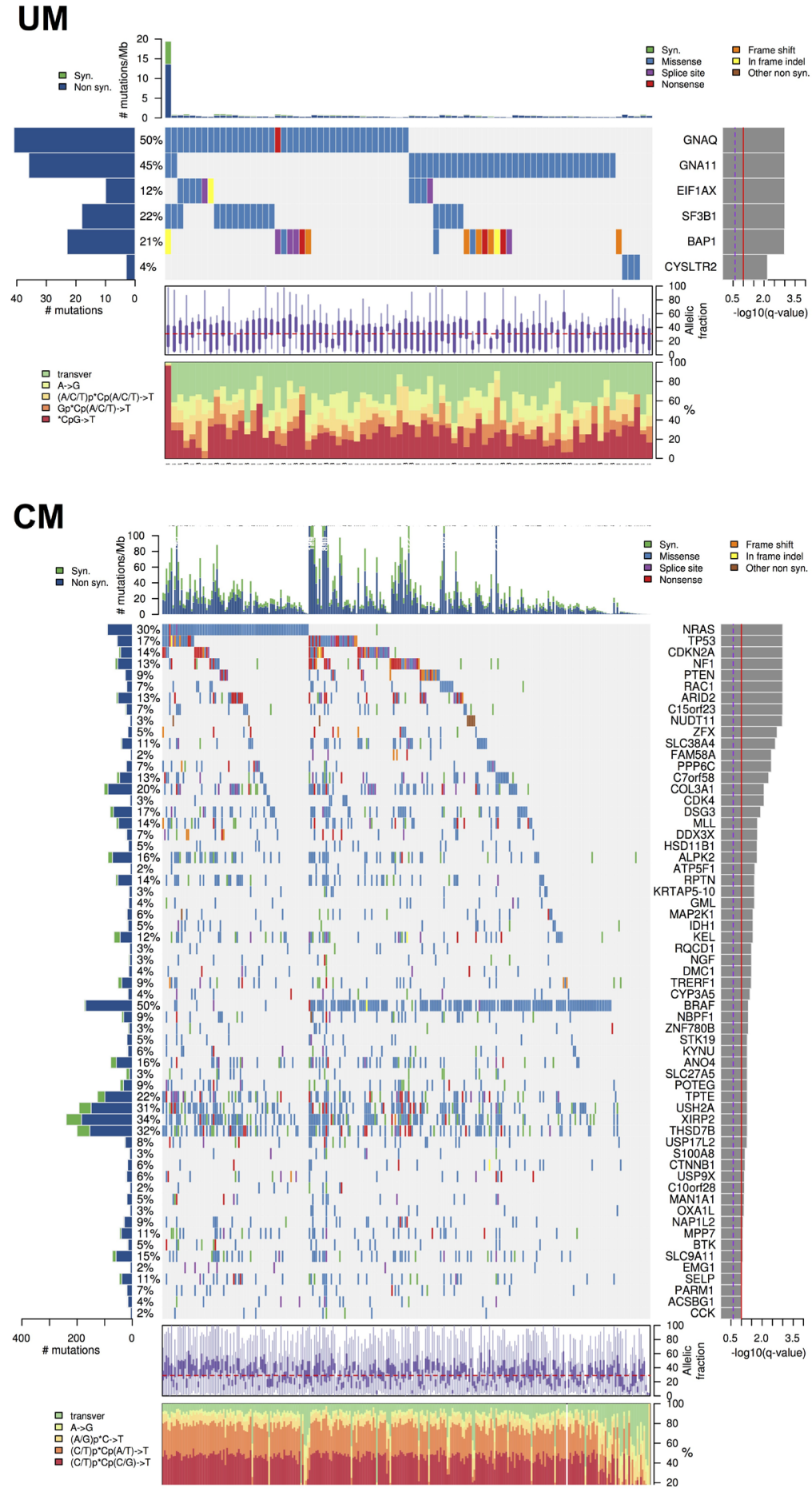

Figure 1. Overview of the genetic landscape of UM and CM based on patient samples from the GDAC Firebrowse Database. A co-mut plot displaying the results from the MutSig2CV 3.1 analysis on $80 \mathrm{UM}$ and $343 \mathrm{CM}$ samples. The top barplot displays the rate of synonymous (green) and non-synonymous (blue) mutations per megabase pairs (Mb), with each bar representing a single patient sample. The right barplot displays the most significantly mutated genes in each cohort and their q-value. The left barplot displays the number of mutations in each of these genes together with a percentage of samples with at least one mutation in that gene. The boxplot below the matrix shows the distributions of allelic fractions in each sample. The bottom plot shows the distribution of SNVs in each patient sample, according to the SNV categorization system on GDAC Firebrowse. 

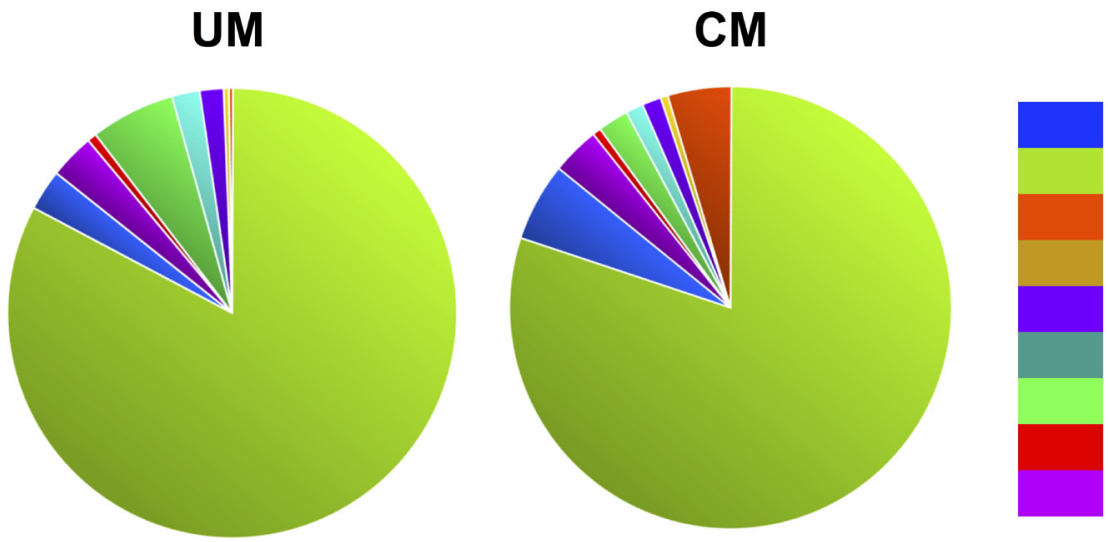

Substitution nonsense
Substitution missense
Substitution synonymous
Insertion inframe
Insertion frameshift
Deletion inframe
Deletion frameshift
Complex
Other

$\begin{array}{cc}\text { UM (\%) } & \mathrm{CM}(\%) \\ 2.9 & 5.7 \\ 82.7 & 80.0 \\ 0.3 & 4.7 \\ 0.4 & 0.5 \\ 1.7 & 1.4 \\ 2.0 & 1.3 \\ 6.1 & 2.2 \\ 0.7 & 0.6 \\ 3.2 & 3.5\end{array}$

Figure 2. Distribution of mutation types in the COSMIC UM and CM samples. An analysis of the types of mutations present in 995 UM and 12,401 CM samples from the COSMIC database is illustrated in the pie chart. Mutation types were color-coded as per the key. Substitution missense mutations were the most frequent type of mutation in both UM and CM samples, accounting for $82.7 \%$ and $80.0 \%$, respectively.

\section{UM}

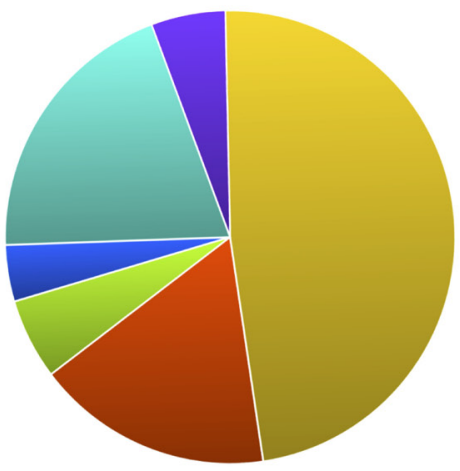

\section{CM}

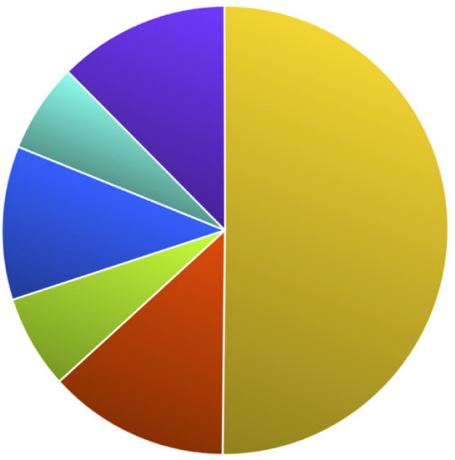

UM (\%) CM (\%)

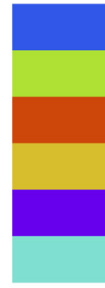

$\begin{array}{lcc}\mathrm{C}: \mathrm{G}>\mathrm{A}: \mathrm{T} & 4.0 & 11.1 \\ \mathrm{C}: \mathrm{G}>\mathrm{G}: \mathrm{C} & 5.8 & 6.8 \\ \mathrm{C}: \mathrm{G}>\mathrm{T}: \mathrm{A} & 17.0 & 13.1 \\ \mathrm{~T}: \mathrm{A}>\mathrm{A}: \mathrm{T} & 48.0 & 50.2 \\ \mathrm{~T}: \mathrm{A}>\mathrm{C}: \mathrm{G} & 5.3 & 12.4 \\ \mathrm{~T}: \mathrm{A}>\mathrm{G}: \mathrm{C} & 19.9 & 6.4\end{array}$

Figure 3. Mutational signature of single nucleotide variants (SNVs) in the COSMIC UM and CM samples. A breakdown of the specific SNVs present on both DNA strands in $577 \mathrm{UM}$ and 7,155 CM samples from the COSMIC database is illustrated in the pie chart. The variants were color-coded as per the key. The T:A>A:T substitution was the most frequent SNV in both UM and CM, accounting for $48.0 \%$ and 50.2\%, respectively. C:G>T:A substitutions were present in $17.0 \%$ and $13.1 \%$ of UM and CM samples, respectively.
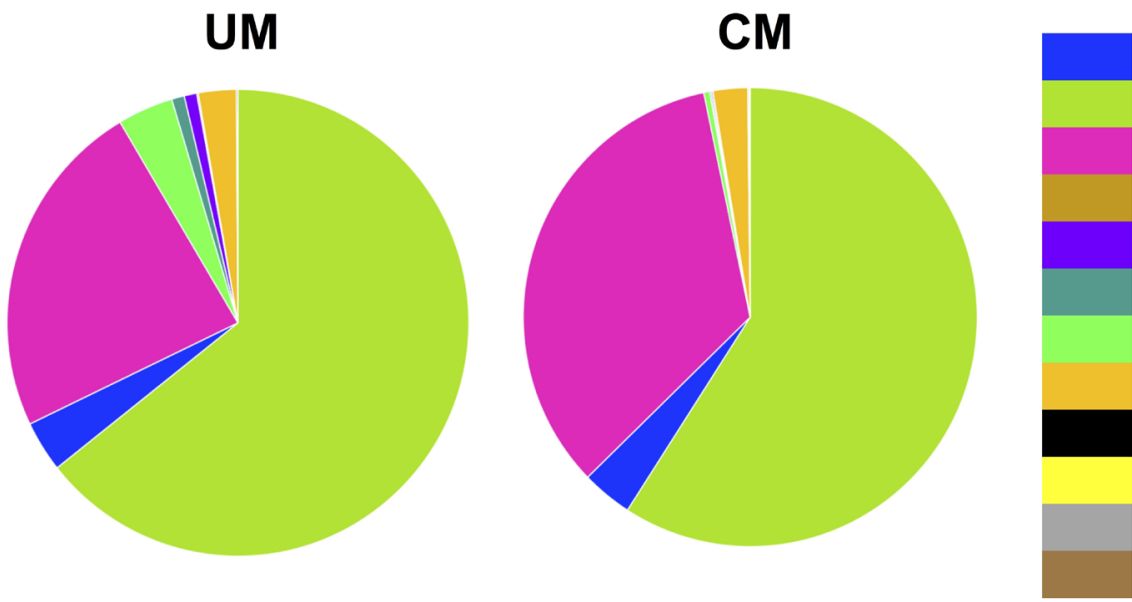

Substitution nonsense

UM (\%) CM (\%)

Substitution missense

3.5

Silent mutation

$64.3 \quad 59.1$

Insertion inframe

$23.6 \quad 34.0$

Insertion frameshift

$3.9 \quad 0.4$

$0.9 \quad 0.1$

Deletion inframe

0.9

0.1

Deletion frameshift

0.1

0.0

Splice site

2.7

2.5

Start codon SNP

$0.1 \quad 0.1$

Nonstop mutation

$-\quad 0.0$

De novo start out of frame

$-\quad 0.0$

De novo start inframe

0.0

Figure 4. Distribution of mutation types in the GDAC Firebrowse UM and CM samples. 80 UM and 343 CM patient samples available from GDAC Firebrowse database were analyzed using MutSig v2.0 according to the types of mutations present. A breakdown of the mutation types in each cohort is illustrated in the pie chart, with color-coded mutation types as per the key. Substitution missense mutations were the most frequent type of mutation in both $\mathrm{UM}$ and CM samples, accounting for $64.3 \%$ and $59.1 \%$, respectively. 
UM had a significantly higher proportion of samples exhibiting C:G>T:A substitutions (17.0\%) compared to CM $(13.1 \%)$ in both strands ( $\mathrm{p}=0.038)$. It was noted that $316 \mathrm{UM}$ samples and 4,985 CM samples exhibited SNVs, however, the specific substitution was unknown (Figure 3).

Distribution of mutation types and single nucleotide variants in GDAC Firebrowse. In the GDAC Firebrowse database, the distribution of mutation types including substitution nonsense, substitution missense, substitution synonymous, insertion inframe, insertion frameshift, deletion inframe, deletion frameshift, splice site, start codon single nucleotide polymorphism (SNP), nonstop mutation, de novo start out of frame and de novo start inframe were analyzed in UM $(n=80)$ and CM $(n=343)$ samples. The patterns of distribution in mutation types were similar, with substitution missense as the most frequent mutation type $(64.3 \%$ and $59.1 \%$, respectively), followed by silent mutation $(23.6 \%$ and $34.0 \%$, respectively, Figure 4 ). Despite the small number of patient samples in GDAC Firebrowse compared with the COSMIC database, similar trends in mutation types and frequencies were observed. All samples were found to have SNVs present. UM samples were analyzed for the following $\mathrm{SNV}$ categories - $\mathrm{CpG}>\mathrm{T}, \mathrm{Cp}(\mathrm{A} / \mathrm{C} / \mathrm{T})>\mathrm{T}, \mathrm{A}>\mathrm{G}$, transverse, indel+null, and double null. CM samples with SNVs were analyzed according to the following SNV categories - $(\mathrm{C} / \mathrm{T})$ $\mathrm{pC}>\mathrm{T},(\mathrm{A} / \mathrm{G}) \mathrm{pC}>\mathrm{T}, \mathrm{A}>\mathrm{G}$, transverse, indel+null and double null. The most frequent SNV category in $\mathrm{UM}$ was $\mathrm{CpG}>\mathrm{T}$, while in $\mathrm{CM}$ it was $(\mathrm{C} / \mathrm{T}) \mathrm{pC}>\mathrm{T})$ (Figure 5). The frequency and pattern of SNVs were unable to be directly compared between UM and CM due to the disparity in their SNV categorization systems, as per the GDAC Firebrowse database. Thus the hypothesis was unable to be tested using statistical significance. However, the MutSig2CV 3.1 analysis revealed that $\mathrm{C}>\mathrm{T}$ was the most frequent $\mathrm{SNV}$ in both $\mathrm{UM}$ and CM. The most common three-base contexts in which C> T occurred in UM was C_G and A_G (non-dipyrimidine sites), and C_G and T_G (dipyrimidine sites), with approximately equivalent rates in each. In $\mathrm{CM}$, the most common three-base context was T_G, followed by T_C, C_C and T_A, with a preponderance featuring dipyrimidine sites (Figure 6).

Molecular signature of UV-induced damage in UM and CM samples. To gain a more in-depth understanding of the link between UV radiation and UM, we next identified genes in UM that were most commonly mutated in CM. From the twenty (20) most frequently mutated genes in the COSMIC UM $(\mathrm{n}=995)$ and CM $(\mathrm{n}=12,401)$ cohorts, the following eight (8) genes were common to both - BRAF, NRAS, TP53, TERT, CDKN2A, PTEN, ARID2, and KMT2C (Figure 7). Many of the genes from this list have been previously linked to UV-induced damage in CM in the literature. The mutated forms of these genes were present in a much higher proportion of CM compared to UM samples (Figure 7C). Across both UM and CM samples, three (3) identical point mutations were observed in BRAF, NRAS, and TP53. The shared mutation in $B R A F$ is characterized by a valine to glutamic acid change at the $600^{\text {th }}$ amino acid (V600E), and resulted from a $\mathrm{T}>\mathrm{A}$ substitution at the $1799^{\text {th }}$ base $(1799 \mathrm{~T}>\mathrm{A})$. This mutation accounted for the most $B R A F$ variants in the UM (36 of 39) and CM samples (4,720 of 9,441). NRAS was mutated in both cancers at codon 61, with Q61R $(182 \mathrm{~A}>\mathrm{G})$ being the only known common substitution. There were two point mutations in TP53 shared between UM and CM - R273C (817C>T) and R248Q (743G>A). Both these TP53 changes co-occurred in one UM sample, however, were mutually exclusive in the CM samples. Based on the GDAC Firebrowse data, 7 significantly mutated genes were identified in UM, as well as 117 genes in CM - however, no shared genes were observed (Table 1).
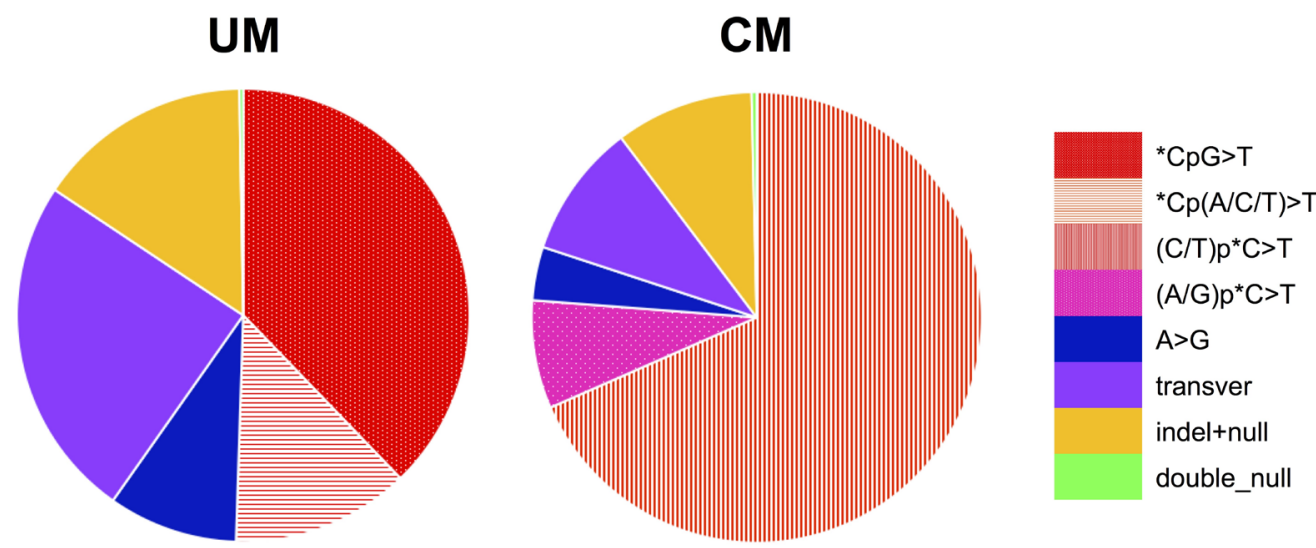

$\begin{array}{cc}\text { UM (\%) } & \text { CM (\%) } \\ 37.8 & - \\ 12.7 & - \\ - & 68.5 \\ - & 7.8 \\ 9.3 & 3.8 \\ 24.6 & 9.6 \\ 15.4 & 9.9 \\ 0.3 & 0.4\end{array}$

Figure 5. Mutational signature of single nucleotide variants (SNVs) in the GDAC Firebrowse UM and CM samples. 80 UM patient samples were analyzed using MutSig v2.0 according to the following SNV categories - $\mathrm{CpG}>\mathrm{T}, \mathrm{Cp}(\mathrm{A} / \mathrm{C} / \mathrm{T})>\mathrm{T}, \mathrm{A}>\mathrm{G}$, transverse, indel+null and double null. $343 \mathrm{CM}$ samples were analyzed using MutSig v2.0 according to the following SNV categories - $(\mathrm{C} / \mathrm{T}) \mathrm{pC}>\mathrm{T},(\mathrm{A} / \mathrm{G}) \mathrm{pC}>\mathrm{T}, \mathrm{A}>\mathrm{G}$, transverse, indel+null and double null. SNVs were color-coded as per the key. The most frequent SNV category in UM was $C p G>T$, while in $C M$ it was $(C / T) p C>T$. Mutation types were color- and pattern-coded as per the key. 
Table 1. Mutated genes in the GDAC Firebrowse UM and CM samples. A mutational analysis of the UM $(n=80)$ and CM $(n=343)$ patient samples determined 7 genes significantly mutated in UM compared to 117 genes significantly mutated in CM. No shared mutated genes were found between the two cohorts.

\begin{tabular}{|c|c|c|c|c|c|c|c|c|c|}
\hline UM & CM & & & & & & & & \\
\hline GNAQ & $B R A F$ & ALPK2 & $M P P 7$ & CD2 & BCM01 & NTN4 & $S A G$ & S100A8 & CCK \\
\hline GNA11 & $X I R P 2$ & AN04 & $M L L 4$ & AMPD3 & $K Y N U$ & OR11H12 & RUFY4 & $0 X A 1 L$ & KRAS \\
\hline$B A P 1$ & THSD7B & SLC9A11 & GLRB & RAC1 & CTNNB1 & $H S D 11 B 1$ & KRTAP5-10 & ZNF595 & FAM55C \\
\hline$S F 3 B 1$ & USH $2 A$ & $R P T N$ & PKDREJ & PРP6C & C1QTNF9 & STK19 & ZNF780B & ACO1 & $L U Z P 1$ \\
\hline EIF1AX & $N R A S$ & $C D K N 2 A$ & OR51S1 & $D D X 3 X$ & PPFIA1 & $M M P 1$ & SLC27A5 & DDX17 & NUDT4 \\
\hline CYSLTR2 & PTPRT & $M L L$ & C20RF16 & C100RF72 & ZNF490 & CYP3A5 & $P O L R 2 B$ & C100RF28 & $M E D 17$ \\
\hline \multirow[t]{7}{*}{ SFRS2 } & $S l$ & $N F 1$ & POTEG & MAP3K5 & IL5RA & $A C S B G 1$ & MCART2 & $E M G 1$ & IFNGR2 \\
\hline & TPTE & ARID2 & TRERF1 & C150RF23 & ADAM33 & $M M P 27$ & CD300E & МYPOP & CSN3 \\
\hline & $D S P$ & C70RF58 & $N B P F 1$ & PARM1 & $Z F X$ & APCS & $R Q C D 1$ & PDK4 & C30RF71 \\
\hline & $C O L 3 A 1$ & $K E L$ & PTEN & LILRB5 & MAP2K1 & CD209 & $N G F$ & EPS8 & UBE2V2 \\
\hline & TP63 & THEMIS & NAP1L2 & GPX5 & $I D H 1$ & RICTOR & CASP8 & C100RF118 & BOLA1 \\
\hline & TP53 & SLC38A4 & PRKAA2 & USP9X & MAN1A1 & $G M L$ & NUDT11 & FAM58A & ZNF589 \\
\hline & DSG3 & SELP & USP17L2 & MUC7 & BTK & $D M C 1$ & $C D K 4$ & ATP5F1 & ZZZ3 \\
\hline
\end{tabular}

\section{Discussion}

These results, based on large cohorts of sequenced cancers, present substantial evidence in support of the hypothesis that the mutational signatures of UM and CM are broadly comparable in terms of UV light damage, and that the pathogenesis of UM may be more dependent on UV light than previously recognized.

UM and CM were found to have a similar distribution of mutation types. The most frequent type, accounting for the majority of mutations, was substitution missense. The pattern of cytosine to thymine (C>T or C:G>T:A) SNVs has often been used as a marker of UV-related damage [29, 30], and was investigated in this study for CM and UM cohorts from both COSMIC and GDAC Firebrowse databases. Based on the collective findings of both patient cohorts, neither the genetic profiles of CM nor UM displayed the classic UV signature [29], defined as $\geq 60 \%$ of mutations being $\mathrm{C}>\mathrm{T}$ transitions at a pyrimidine site, with at least $5 \%$ being CC $>$ TT tandem substitutions. This is despite the widespread understanding that $\mathrm{CM}$ is etiologically linked to UV radiation. Unfortunately, neither cohort allowed CC $>$ TT tandem substitutions to be assessed. Our results showed that in the COSMIC cohort, C:G>T:A changes accounted for a significantly higher proportion of SNVs in UM compared to CM. This result is inconsistent with a recent study that reported a significantly higher percentage of SNVs were C $>\mathrm{T}$ in $\mathrm{CM}$ when compared to UM (approximately $85 \%$ vs $35 \%$ of SNVs, respectively) [31], as well as other whole-genome sequencing studies [32]. Our results from the far smaller Firebrowse cohort were more consistent with these previous reports, however, the majority of SNVs were $\mathrm{C}>\mathrm{T}$ in both the Firebrowse UM and CM cohorts. This is in line with multiple whole genome sequencing studies in CM [32-34]. It has also been reported that melanomas in sun-protected areas (acral, mucosal, uveal) featured $\mathrm{C}>\mathrm{T}$ as the most common $\mathrm{SNV}$ overall; however, it was noted that a key difference between sun-exposed and sun-protected melanomas was an excess of $\mathrm{C}>\mathrm{T}$ transitions at dipyrimidine, rather than non-dipyrimidine sites (a more specific indicator of UV-induced DNA damage) [32]. When considering the three-base context in which $\mathrm{C}>\mathrm{T}$ transitions occurred, the vast majority of $\mathrm{C}>\mathrm{T}$ transitions in $\mathrm{CM}$ were at dipyrimidine sites, consistent with UV-related mutagenesis. In $\mathrm{UM}, \mathrm{C}>\mathrm{T}$ transitions were approximately equivalent at dipyrimidine (CTG, TCG) and non-dipyrimidine (ACG, GCG). This finding may reflect a distinction between UM and CM in their relationship to UV radiation, but at the very least, does not exclude the role of UV radiation in either cancer. The genome-wide dipyrimidine status of $C: G>T: A$ transition sites was unable to be determined in the COSMIC group of patients.

Of note, the sample sizes of both our Firebrowse UM cohort and the study by Royer-Bertrand and colleagues were considerably smaller and based in different geographical areas than the COSMIC cohort [31]. Considering the COSMIC findings are based on a much more substantial cohort size, these results warrant further investigation into the relationship between UV radiation and UM, which may be more similar to CM than previously thought. It is also possible that the significance of UV radiation in the development of UM varies according to geographical location and the associated demographics, genetics, and intensity of UV exposure found in that area.

Of note, $C: G>T: A$ transitions did not feature as the most common SNV in either the COSMIC UM or CM cohorts. Instead, $T: A>A: T$ accounted for approximately half of the SNVs in both melanoma types. This is inconsistent with studies on the genomic landscape of CM [32-34]. However, there are several possible explanations for this finding. In both UM and CM, the mutation hotspots in some of their most frequently mutated genes feature a T:A $>\mathrm{A}: \mathrm{T}$ substitution. For example, GNAQ and GNA11 are well-established 


\section{UM}

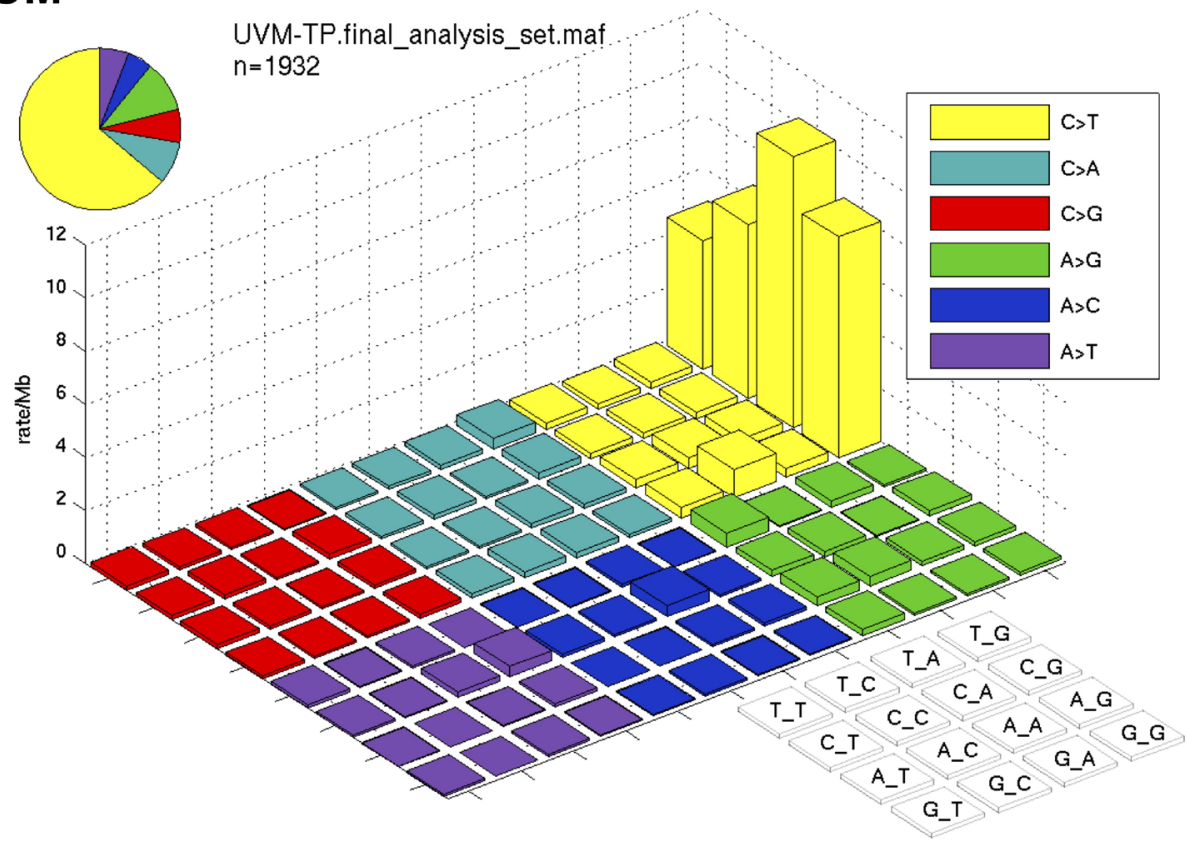

\section{CM}

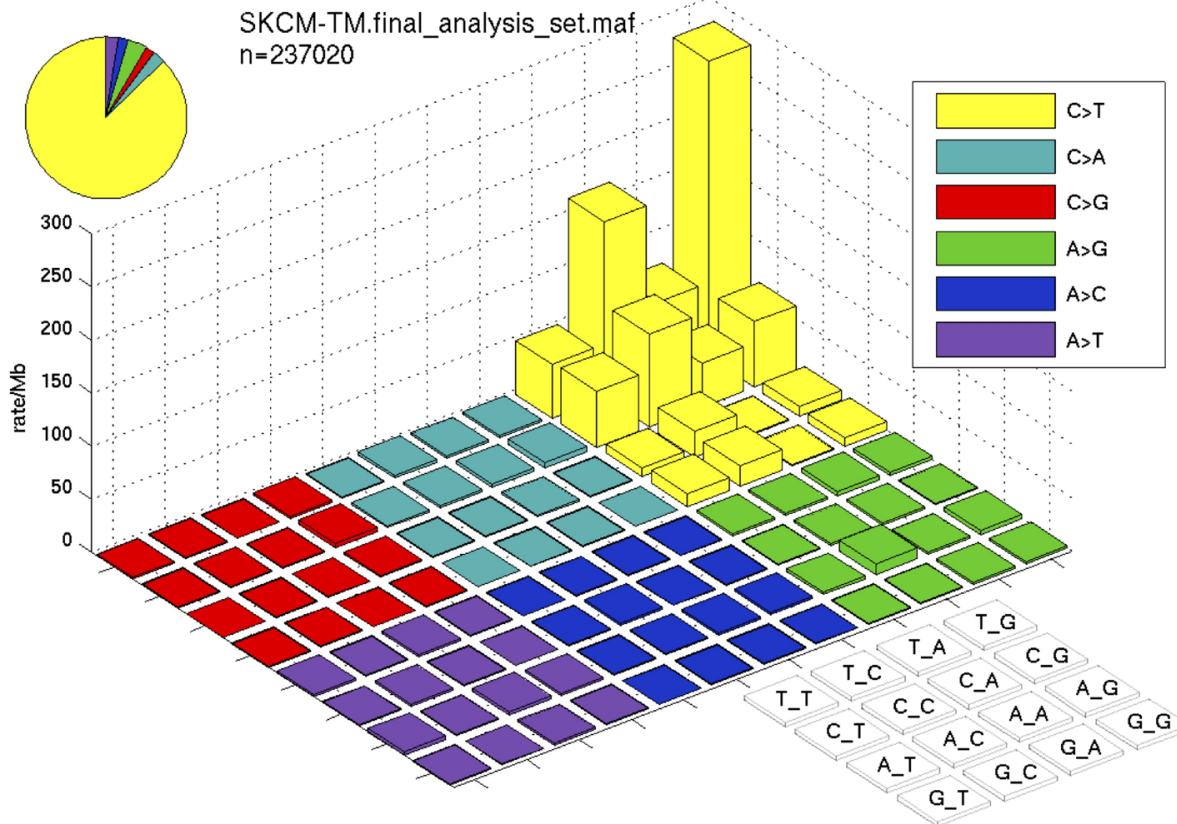

Figure 6. Lego plot of mutation rates of SNVs in GDAC Firebrowse UM and CM samples. Lego plots were generated using a MutSig2CV 3.1 analysis on $80 \mathrm{UM}$ and $343 \mathrm{CM}$ samples. The total number of substitutions detected in UM and CM were 1,932 and 237,020, respectively. Each bin is normalized by base coverage for that bin. The height of each bin is representative of the mutation rate per million bases (Mb). Different SNV types are represented in colors indicated in the key on the upper right of each figure. The $4 \times 4$ legend on the lower right indicates the three-base context for each mutation. The pie chart on the upper left illustrates the breakdown of specific SNV types. The most frequent SNV type in both UM and CM was C>T substitutions.

driver genes in UM that are mutated in the majority of primary $(85 \%)$ and metastatic UM (96\%) $[35,36]$. These genes are highly homologous and both are most commonly modified by an $\mathrm{A}>\mathrm{T}$ transition at codon 209. GNAQ/11 codon 209 mutations are said to be analogous to the hotspot $B R A F$ mutation (V600E; $1799 \mathrm{~T}>\mathrm{A}$ ), which is present in up to $70 \%$ of CM $[37,38]$. This was reflected in our findings when considering SNVs on the coding strand alone $-\mathrm{A}>\mathrm{T}$ was the 
A

UM

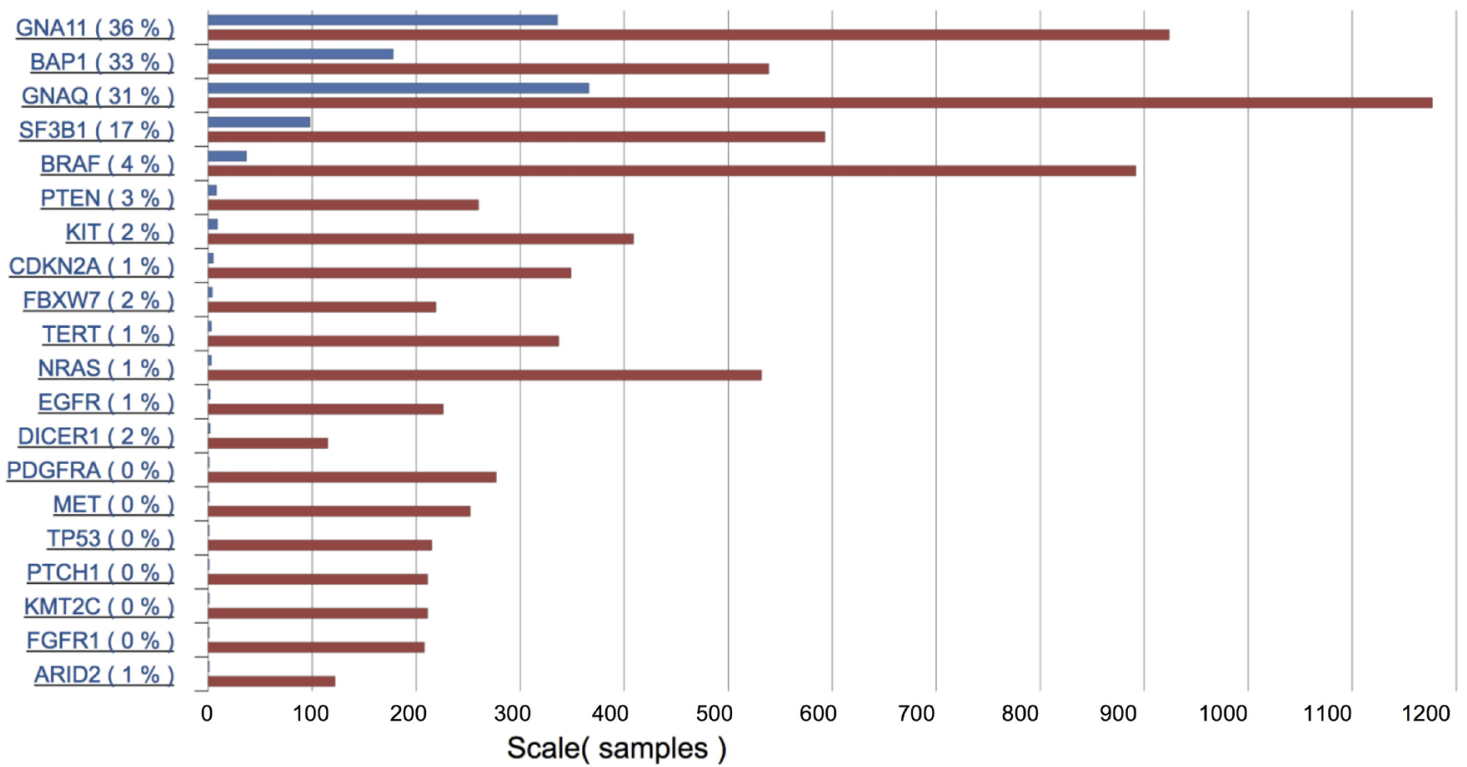

B

\section{CM}
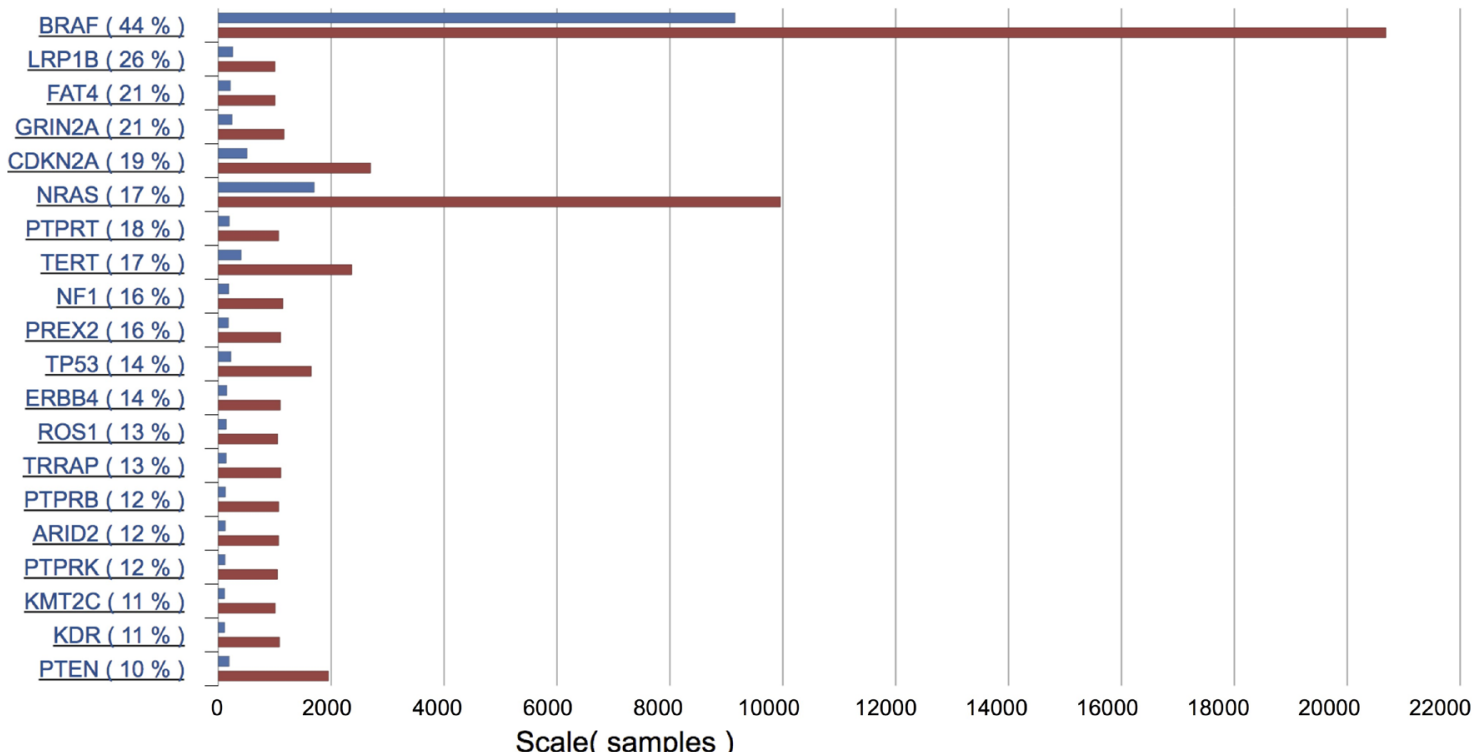

Samples with mutations $\square$ All samples

C

$\begin{array}{ccccccccc}\% & \text { BRAF } & \text { PTEN } & \text { CDKN2A } & \text { TERT } & \text { NRAS } & \text { ARID2 } & \text { TP53 } & \text { KMT2C } \\ \text { UM } & 4 & 3 & 1 & 1 & 1 & 1 & <1 & <1 \\ \text { CM } & 44 & 10 & 19 & 17 & 17 & 12 & 14 & 11\end{array}$

Figure 7. Most frequently mutated genes in COSMIC UM and CM samples. Histograms describing the top 20 genes mutated in 995 UM (A) and 12,447 CM (B) patient samples available from the Sanger Institute's COSMIC database. The bars show the sample counts for the specified gene - the total count represented by red bars, and the mutant count represented by blue bars. The number of samples tested for each gene is represented as red bars, and the number of samples with the mutated form of the gene is represented as blue bars. Mutation rates were calculated as a percentage of samples containing a mutated form of the gene divided by the total number of samples tested for that gene. This percentage is indicated in brackets adjacent to the corresponding gene. Cross-correlation of the 20 most mutated genes in each tumor found that eight (8) frequently mutated genes were shared between UM and CM - BRAF, NRAS, TP53, CDKN2A, TERT, PTEN, ARID2, and KMT2C (C). All 8 genes were mutated at higher rates in CM than UM. 
most common SNV for UM, while for CM it was T>A (Suppl Figure $\mathrm{S} 1$ ). Other than in $B R A F, \mathrm{~T}: \mathrm{A}>\mathrm{A}: \mathrm{T}$ transversions have been rarely observed in CM [39]. Thus, it is possible that the high proportion of UM and CM samples with GNAQ/11 and $B R A F$ mutations respectively may contribute to why $\mathrm{T}: \mathrm{A}>\mathrm{A}: \mathrm{T}$ was the most frequent SNV in both cancers.

As $\mathrm{A}$ and $\mathrm{T}$ are complementary bases, it has been suggested that a similar, potentially UV-related mechanism may underlie $G N A Q / 11$ and BRAF mutations [4, 37, 40, 41], despite the fact that $\mathrm{T}: \mathrm{A}>\mathrm{A}: \mathrm{T}$ transversions are not strictly $\mathrm{UV}$ signature mutations. Interestingly, single $\mathrm{C}>\mathrm{T}$ and tandem CC>TT substitutions are in fact present in GNA11 codons 182-183, both in the literature and in this study (Suppl Figure S2), strongly supporting a role for UV radiation in UM pathogenesis [36]. It is proposed that these hallmark UVB-related mutations do not manifest in codon 209 since a $\mathrm{C}>\mathrm{T}$ change in its sequence would simply translate into a stop codon or silent mutation. Thus, T:A $>$ A:T substitutions in codon 209 of GNAQ/11 and in BRAF V600E may represent analogous, UV-related yet selection-driven mutations [37]. Although the underlying mechanism is not fully understood, similarities between these sites, such as the presence of a CpA nucleotide, have been suspected to contribute to photoproduct formation [37].

Another explanation for the unexpectedly higher frequency of $\mathrm{T}: \mathrm{A}>\mathrm{A}: \mathrm{T}$ substitutions include a dilutional effect from non-specific mutations arising from UV-induced oxidative damage, which occur in addition to the typical $\mathrm{C}>\mathrm{T}$ changes that result from DNA photoproducts (e.g. CPDs) [42].

Commonly mutated genes in UM and CM. Eight genes were found to be commonly mutated in both UM and CM - BRAF, NRAS, TP53, CDKN2A, TERT, PTEN, ARID2, and $K M T 2 C$. In general, a higher proportion of CM exhibited mutations in these shared genes than UM.

a) Shared UV-associated point mutations. Mutations in the $B R A F$ gene have been described in a wide variety of human cancers, with the highest frequency in primary CM [38]. $B R A F$ mutations are generally thought of as rare occurrences in UM. In recent years, the most common and well-known $B R A F$ mutation in CM, V600E, has become targetable with systemic therapies (e.g. vemurafenib). Although this successfully improved survival outcomes for metastatic CM driven by mutated $B R A F$-dependent MAPK upregulation, it failed to translate into similar positive outcomes for metastatic UM patients, with metastatic UM excluded from many clinical trials partly due to reports of a lack of $B R A F$ mutations in UM $[36,38,43,44]$. This analysis confirms that while BRAF mutations are more common in CM, a significant minority of $\mathrm{UM}$ also displaying $B R A F$ mutations and that the mutation of $B R A F$ is the most frequently occurring mutated in both UM and CM. These findings are consistent with previous laboratory and clinical results demonstrating BRAF V600E mutation in UM cell lines [45, 46], iris tumor specimens [47], ciliary body uveal melanoma [48], and choroidal melanomas $[48,49]$. BRAF V600E does not arise from single or tandem
$\mathrm{C}>\mathrm{T}$ substitutions and was initially thought to be unrelated to $U V$ radiation and hence, the role of $U V$ radiation in $B R A F$ mutagenesis was questioned [38]. More recently, it has become increasingly recognized that $B R A F$ mutagenesis results from UV-related mechanisms, including UVA photoreactions or error-prone translesion DNA synthesis following non-specific mutations from UV-induced oxidative stress [41].

In CM, BRAF V600E conveys aggressiveness and increased metastatic risk, and is more often found in patients who are younger ( $<50$ y.o.), have high naevi counts, and a positive family history of CM $[50,51]$. BRAF mutations in CM are most likely in sites with intermittent high-intensity sun exposure (e.g. history of sunburns) [11, 52], and are generally more prevalent in melanomas from sun-exposed skin sites $[11,53,54]$. A similar trend has been observed in UM; melanomas of the iris, the part of the uveal tract that receives the most UV radiation, exhibit a higher frequency (48\%) of BRAF V600E mutations [47], compared with the ciliary body (20\%) and choroidal melanomas (40\%) [48]. This could be interpreted as an association between the amount of UV exposure at a particular site and the proportion of its tumors with mutant $B R A F$, and this is consistent with our finding that the proportion of CM with $B R A F$ mutations was 10 -fold higher than in UM. Alternative reasons for the lower frequency of $B R A F$ mutations in UM include the known heterogeneous distribution of cells, and therefore $B R A F$ positive cells, in UM tumors, insufficient tumor sampling, a small proportion of UM located in sun exposed areas of the eye, and the redundancy of $B R A F$ mutations due to prior MAPK pathway upregulation by $G N A Q / 11$ mutations, which occur early in UM tumorigenesis $[48,55]$.

$B R A F$ mutations were not present in the Firebrowse UM cohort. It is possible that $B R A F$ mutations may be associated with only a subset of UM, such as patients from a particular geographic area, as hypothesized by Malaponte et al. [49]. It may also be that UM in European patients, such as the Mediterranean BRAF-positive case in Malaponte et al. [49] and the United Kingdom (UK)-based COSMIC cohort, have a predisposition to develop $B R A F$ mutations compared to those in the United States of America (USA)-based Firebrowse cohort, although further research is warranted regarding the geographical variation in mutant $B R A F$ frequency [49].

In addition to $B R A F 1799 \mathrm{~T}>\mathrm{A}$, three other identical point mutations, NRAS (Q61R (182A >G)) and TP53 (R273C $(817 \mathrm{C}>\mathrm{T})$, R248Q (743G $>\mathrm{A})$ ) were shared between UM and CM. NRAS is the most frequently mutated RAS oncogene in CM. Although it is closely related to BRAF in the MAPK pathway, NRAS mutations have not been as successfully targeted with systemic therapies $[50,56]$. Mutations in NRAS are present in around $15 \%$ of all non-uveal melanomas, and occur at hotspots in codons 12,13 and $61.90 \%$ of NRAS mutations in CM are in codon 61; these tend to be mutually exclusive with BRAF V600 variants, although they both convey constitutive activity of the same downstream effectors 
(e.g. MAPK pathway), and have been linked to UV radiation [57-59]. NRAS mutations mainly occur in CM arising from sun-exposed areas, particularly if the exposure is chronic [60]. This is in contrast to $B R A F$ mutations, which are more common in intermittently UV-exposed skin. Mutant NRAS is also more common in populations subject to a higher (e.g. Australia) rather than lower (e.g. Northern Europe) UV radiation intensity. On a molecular level, the NRAS codon 61 is a UV-sensitive site, where its sequence context and structure render it vulnerable to CPD formation $[52,61]$.

Both BRAF codon 600 and NRAS codon 61 variants can be found in all stages of melanoma evolution, from benign melanocytic naevi to CM metastases. A recent study found that BRAF V600E was the only mutation present in the very early stages of melanomagenesis (e.g. benign naevi), while $N R A S$ and other $B R A F$ variants emerged later, such as in intermediate lesions or melanomas in situ that had already acquired other oncogenic alterations [62]. In addition, Demunter et al. proposed that exon 2 mutations, such as Q61R, occur during the later stages of tumorigenesis and therefore are more likely associated with UV-induced melanoma progression rather than initiation [61]. As such, the presence of NRAS mutations, particularly Q61R, may imply that UM or at least a subgroup of UM has UV-dependent tumor progression, assuming UM responds to UV radiation in a similar manner to $\mathrm{CM}$.

TP53 is the most commonly mutated gene in human cancer, with alterations in approximately $50 \%$ of cancers leading to inactivation of its pathway $[63,64]$. It is also widely appreciated that TP53 is a UV target gene. This was originally and best exemplified in non-melanoma skin cancers, in which $\mathrm{C}>\mathrm{T}$ and $\mathrm{CC}>\mathrm{TT}$ tandem substitutions at dipyrimidine sites in TP53 are early, frequent events [65]. The mutation spectrum of TP53 has since been used as a tool to predict the significance of UV radiation, as well as other carcinogens, in the etiology of different human cancers [63, 66, 67]. In UM, the inhibition of the tumor suppressor effects of TP53 usually occurs downstream of p53 and thus actual TP53 gene mutations are rare - a contributor to the argument that UV is not a prominent etiological factor in UM [68-70]. However, two TP53 point mutations, R273C and R248Q, were found to be shared between the COSMIC UM and CM cohorts. These mutations are both documented TP53 mutants [71], and derived from C:G>T:A substitutions that are suggestive of UV-related mutagenesis [29]. These findings are congruent with previous reports that the majority of TP53 mutations are $\mathrm{C}: \mathrm{G}>\mathrm{T}: \mathrm{A}$, and although $\mathrm{CC}>\mathrm{TT}$ transitions have also been observed [72], they were not detected in the current study. In addition, $\mathrm{R} 273 \mathrm{C}$ ( $\mathrm{R} 270 \mathrm{C}$ in mice) corresponds to one of the five mutations induced in the BRAF V600E-positive CM mouse model following UV exposure $[73,74]$. In CM, TP53 mutations appear to be non-essential for tumorigenesis [72], yet are shown to promote BRAF V600E-driven melanomagenesis [73]. It is not known whether a similar phenomenon occurs in UM. b) Shared mutated genes. Although mutations in the coding region of the TERT gene are uncommon, the TERT promoter region is considered a target of UV damage, and UV signature mutations have been observed here in a wide range of cancers including CM, non-melanoma skin cancers, and conjunctival melanoma [75]. In our study, two TERT promoter mutations were identified in the COSMIC UM cohort at the established hotspot positions of -124 and - 146 bases upstream from the start codon. These changes are known to increase promoter activity in CM and are present in up to 70\% CM [75-77]. Our findings are consistent with previous case reports of TERT promoter mutations in UM, at a similar frequency of $1-2 \%$ samples $[78,79]$. This is markedly lower than the mutation frequencies observed in CM and conjunctival melanoma (32\%) [80]. Considering the link between UV and TERT mutations, it has been suggested that this difference represents a genetic, and possibly etiologic, distinction between CM and UM, particularly with regards to UV radiation [80]. Although our finding of $\mathrm{C}>\mathrm{T}$ changes in a known UV target gene in $\mathrm{UM}$ is not definitive of a causal relationship, it implies the possibility of UV radiation as a factor in UM development in a subset of patients cannot be excluded.

The CDKN2A gene is classically associated with CM and similar to BRAF, NRAS, and TP53 is a known driver of melanomagenesis [50,81,82], with inactivation of the $C D K N 2 A$ gene a major predisposing factor to the development of CM. Germline CDKN2A mutations are strongly linked to familial melanoma and have been even suggested to convey susceptibility to UM $[83,84]$. There is also evidence for an association between the CDKN2A mutation and UV radiation. It has been suggested that the most significant UV target mutations in CM occur in tumor suppressor genes, CDKN2A and TP53 due to their downstream effects on the $\mathrm{Rb}$ and p53 pathways, respectively $[85,86]$, and CM and cutaneous squamous cell carcinomas harbor a higher number of UVB signature mutations in CDKN2A compared to non-skin cancer types [39]. However, C:G>T:A transitions in $C D K N 2 A$ were not observed in the current study, where all modifications detected in both COSMIC UM and $\mathrm{CM}$ cohorts were deletions, rather than more commonly documented mechanisms of CDKN2A inactivation of point mutations (predominantly $\mathrm{C}: \mathrm{G}>\mathrm{T}: \mathrm{A}$ ) or promoter hypermethylation $[87,88]$. Deletions in $C D K N 2 A$ have been seen in other investigations [39]. However, their significance with regards to the etiological role of UV in UM is unclear.

In the current study, PTEN mutations were predominantly C:G>T:A transitions in both CM and UM. This is consistent with the literature, as UV radiation has already been implicated in the induction of mutant PTEN [8]. PTEN itself is a well-known tumor suppressor gene that often co-occurs with BRAF V600E in CM and has been observed to act as a gatekeeper against UV-induced DNA damage repair [89, 90]. As such, PTEN mutations in both UM and CM may be consistent with a shared UV-related etiology between 
the two melanoma types and may result from, yet facilitate, UV-induced melanomagenesis.

The remaining shared genes, ARID2 and KMT2C, although present in only a small fraction of UM, may warrant further investigations to determine their significance. Both are known to undergo inactivation in melanocytic lesions $[81,91]$. ARID2 encodes for part of a chromatin remodeling complex and is significantly mutated in CM with a high fraction of $\mathrm{C}>\mathrm{T}$ transitions, characteristic of a UVB-induced mutation [85]. KMT2C encodes a histone methyltransferase to regulate genomic instability and epigenetic changes [91], however, it has not been explicitly associated with UV radiation to date.

Therefore, neither of the CM nor UM cohorts were found to display a classic UV signature, despite the accepted influence of UV radiation in the pathogenesis of CM. However, our results show there are more genetic similarities between UM and CM than previously thought, with at least a subset of UM tumors harboring mutations in several known cancer genes classically associated with CM and/or UV light exposure - BRAF, NRAS, CDKN2A, PTEN, TP53, TERT, ARID2, and KMT2C. In addition, this study showed a large cohort of UM patient samples exhibited a significantly higher frequency of $\mathrm{C}: \mathrm{G}>\mathrm{T}$ :A changes, often used a surrogate measure of UV-related DNA mutagenesis, than CM patients. Together with the identification of well-established UV-target genes in UM, such as TP53 and TERT promoter mutations, these results suggest that on the basis of mutational signature analysis, an etiological relationship between UV radiations and UM cannot be excluded.

Supplementary information is available in the online version of the paper.

Acknowledgments: Dr. Aparna Jayachandran for assistance in database interpretation and manuscript editing.

\section{References}

[1] VAN DEN BOSCH T, KILIC E, PARIDAENS D, DE KLEIN A. Genetics of uveal melanoma and cutaneous melanoma: two of a kind? Dermatol Res Pract 2010; 2010: 360136. https://doi.org/10.1155/2010/360136

[2] SMOLKOVA B, HORVATHOVA KAJABOVA V, ZMETAKOVA I, KALINKOVA L, CZANNER G et al. Role of epigenetic deregulation in hematogenous dissemination of malignant uveal melanoma. Neoplasma 2018; 65: 840-854. https://doi.org/10.4149/neo_2018_180420N261

[3] GOH AY, LAYTON CJ. Evolving systemic targeted therapy strategies in uveal melanoma and implications for ophthalmic management: a review. Clin Exp Ophthalmol 2016; 44: 509-519. https://doi.org/10.1111/ceo.12688

[4] BESARATINIA A, PFEIFER GP. Sunlight ultraviolet irradiation and BRAF V600 mutagenesis in human melanoma. Hum Mutat 2008; 29: 983-991. https://doi.org/10.1002/ humu. 20802
[5] CADET J, WAGNER JR. DNA base damage by reactive oxygen species, oxidizing agents, and UV radiation. Cold Spring Harb Perspect Biol 2013; 5: a012559. https://doi.org/10.1101/ cshperspect.a012559

[6] IKEHATA H, ONO T. The mechanisms of UV mutagenesis. J Radiat Res 2011; 52: 115-125. https://doi.org/10.1269/ jrr.10175

[7] PFEIFER GP, YOU YH, BESARATINIA A. Mutations induced by ultraviolet light. Mutat Res 2005; 571: 19-31. https://doi.org/10.1016/j.mrfmmm.2004.06.057

[8] GARIBYAN L, FISHER DE. How sunlight causes melanoma. Curr Oncol Rep 2010; 12: 319-326. https://doi.org/10.1007/ s11912-010-0119-y

[9] DOUKI T, PERDIZ D, GROF P, KULUNCSICS Z, MOUSTACCHI E et al. Oxidation of guanine in cellular DNA by solar UV radiation: biological role. Photochem Photobiol 1999; 70: 184-190.

[10] WHITEMAN DC, WHITEMAN CA, GREEN AC. Childhood sun exposure as a risk factor for melanoma: a systematic review of epidemiologic studies. Cancer Causes Control 2001; 12: 69-82. https://doi.org/10.1023/a:1008980919928

[11] MALDONADO JL, FRIDLYAND J, PATEL H, JAIN AN, BUSAM K et al. Determinants of BRAF mutations in primary melanomas. J Natl Cancer Inst 2003; 95: 1878-1890. https://doi.org/10.1093/jnci/djg123

[12] EGAN KM, SEDDON JM, GLYNN RJ, GRAGOUDAS ES, ALBERT DM. Epidemiologic aspects of uveal melanoma. Surv Ophthalmol 1988; 32: 239-251. https://doi. org/10.1016/0039-6257(88)90173-7

[13] HU DN. Photobiology of ocular melanocytes and melanoma. Photochem Photobiol 2005; 81: 506-509. https://doi. org/10.1562/2004-08-24-IR-289

[14] MARGO CE, MULLA Z, BILLIRIS K. Incidence of surgically treated uveal melanoma by race and ethnicity. Ophthalmology 1998; 105: 1087-1090. https://doi.org/10.1016/ S0161-6420(98)96012-2

[15] STANG A, PARKIN DM, FERLAY J, JOCKEL KH. International uveal melanoma incidence trends in view of a decreasing proportion of morphological verification. Int J Cancer 2005; 114: 114-123. https://doi.org/10.1002/ ijc. 20690

[16] SEDDON JM, GRAGOUDAS ES, GLYNN RJ, EGAN KM, ALBERT DM et al. Host factors, UV radiation, and risk of uveal melanoma. A case-control study. Arch Ophthalmol 1990; 108: 1274-1280. https://doi.org/10.1001/archopht.1990.01070110090031

[17] ABDEL-RAHMAN MH, PILARSKI R, EZZAT S, SEXTON J, DAVIDORF FH. Cancer family history characterization in an unselected cohort of 121 patients with uveal melanoma. Fam Cancer 2010; 9: 431-438. https://doi.org/10.1007/ s10689-010-9328-7

[18] BOETTNER EA, WOLTER JR. Transmission of the ocular media. Investigative Ophthalmology and Visual Science 1962; 1: 776-783.

[19] LERMAN S. Radiant energy and the eye. Macmillian Publishing Co., Inc., New York 1980: 162-163. 
[20] KESSEL L, LUNDEMAN JH, HERBST K, ANDERSEN TV, LARSEN M. Age-related changes in the transmission properties of the human lens and their relevance to circadian entrainment. J Cataract Refract Surg 2010; 36: 308-312. https:// doi.org/10.1016/j.jcrs.2009.08.035

[21] CRONLEY-DIXON J, ROSEN ES, MARSHALL J. Hazards of light: myths and realities of the eye and skin. Oxford Pergamon Press 1986: 145.

[22] ZIGMAN S. Effects of near ultraviolet radiation on the lens and retina. Doc Ophthalmol 1983; 55: 375-391. https://doi. org/10.1007/bf00161292

[23] LI W, JUDGE H, GRAGOUDAS ES, SEDDON JM, EGAN KM. Patterns of tumor initiation in choroidal melanoma. Cancer Res 2000; 60: 3757-3760.

[24] FORBES SA, BEARE D, GUNASEKARAN P, LEUNG K, BINDAL N et al. COSMIC: exploring the world's knowledge of somatic mutations in human cancer. Nucleic Acids Res 2015; 43: D805-811. https://doi.org/10.1093/nar/gku1075

[25] BROAD INSTITUTE TCGA GENOME DATA ANALYSIS CENTER Mutation Analysis (MutSig v2.0). 2016.

[26] BROAD INSTITUTE TCGA GENOME DATA ANALYSIS CENTER, Mutation Analysis (MutSig v2.0). 2016, Broad Institute of MIT and Harvard.

[27] BROAD INSTITUTE TCGA GENOME DATA ANALYSIS CENTER, Mutation Analysis (MutSig 2CV v3.1). 2016, Broad Institute of MIT and Harvard.

[28] BROAD INSTITUTE TCGA GENOME DATA ANALYSIS CENTER Mutation Analysis (MutSig 2CV v3.1). 2016.

[29] BRASH DE. UV signature mutations. Photochem Photobiol 2015; 91: 15-26. https://doi.org/10.1111/php.12377.

[30] ALEXANDROV LB, NIK-ZAINAL S, WEDGE DC, APARICIO SA, BEHJATI S et al. Signatures of mutational processes in human cancer. Nature 2013; 500: 415-421. https://doi. org/10.1038/nature 12477

[31] ROYER-BERTRAND B, TORSELLO M, RIMOLDI D, EL ZAOUI I, CISAROVA $\mathrm{K}$ et al. Comprehensive Genetic Landscape of Uveal Melanoma by Whole-Genome Sequencing. Am J Hum Genet 2016; 99: 1190-1198. https://doi. org/10.1016/j.ajhg.2016.09.008

[32] KRAUTHAMMER M, KONG Y, HA BH, EVANS P, BACCHIOCCHI A, et al. Exome sequencing identifies recurrent somatic RAC1 mutations in melanoma. Nat Genet 2012; 44: 1006-1014. https://doi.org/10.1038/ng.2359

[33] GREENMAN C, STEPHENS P, SMITH R, DALGLIESH GL, HUNTER $C$ et al. Patterns of somatic mutation in human cancer genomes. Nature 2007; 446: 153-158. https://doi. org/10.1038/nature05610

[34] PLEASANCE ED, CHEETHAM RK, STEPHENS PJ, MCBRIDE DJ, HUMPHRAY SJ et al. A comprehensive catalogue of somatic mutations from a human cancer genome. Nature 2010; 463: 191-196. https://doi.org/10.1038/nature08658

[35] KRANTZ BA, DAVE N, KOMATSUBARA KM, MARR BP, CARVAJAL RD. Uveal melanoma: epidemiology, etiology, and treatment of primary disease. Clin Ophthalmol 2017; 11: 279-289. https://doi.org/10.2147/OPTH.S89591
[36] VAN RAAMSDONK CD, GRIEWANK KG, CROSBY MB, GARRIDO MC, VEMULA $S$ et al. Mutations in GNA11 in uveal melanoma. N Engl J Med 2010; 363: 2191-2199. https://doi.org/10.1056/NEJMoa1000584

[37] BESARATINIA A, PFEIFER GP. Uveal melanoma and GNA11 mutations: a new piece added to the puzzle. Pigment Cell Melanoma Res 2011; 24: 18-20. https://doi.org/10.1111/ j.1755-148X.2010.00821.x

[38] DAVIES H, BIGNELL GR, COX C, STEPHENS P, EDKINS $S$ et al. Mutations of the BRAF gene in human cancer. Nature 2002; 417: 949-954. https://doi.org/10.1038/nature00766

[39] HOCKER T, TSAO H. Ultraviolet radiation and melanoma: a systematic review and analysis of reported sequence variants. Hum Mutat 2007; 28: 578-588. https://doi.org/10.1002/ humu.20481

[40] DE LANGE MJ, RAZZAQ L, VERSLUIS M, VERLINDE S, DOGRUSOZ $M$ et al. Distribution of GNAQ and GNA11 Mutation Signatures in Uveal Melanoma Points to a Light Dependent Mutation Mechanism. PLoS One 2015; 10: e0138002. https://doi.org/10.1371/journal.pone.0138002

[41] THOMAS NE, BERWICK M, CORDEIRO-STONE $M$. Could BRAF mutations in melanocytic lesions arise from DNA damage induced by ultraviolet radiation? J Invest Dermatol 2006; 126: 1693-1696. https://doi.org/10.1038/ sj.jid.5700458

[42] KADEKARO AL, KAVANAGH RJ, WAKAMATSU K, ITO $S$, PIPITONE MA et al. Cutaneous photobiology. The melanocyte vs. the sun: who will win the final round? Pigment Cell Res 2003; 16: 434-447. https://doi.org/10.1034/j.16000749.2003.00088.x

[43] COHEN Y, GOLDENBERG-COHEN N, PARRELLA P, CHOWERS I, MERBS SL et al. Lack of BRAF mutation in primary uveal melanoma. Invest Ophthalmol Vis Sci 2003; 44: 2876-2878. https://doi.org/10.1167/iovs.02-1329

[44] WEBER A, HENGGE UR, URBANIK D, MARKWART A, MIRMOHAMMADSAEGH A et al. Absence of mutations of the BRAF gene and constitutive activation of extracellular-regulated kinase in malignant melanomas of the uvea. Lab Invest 2003; 83: 1771-1776. https://doi.org/10.1097/01. lab.0000101732.89463.29

[45] CALIPEL A, LEFEVRE G, POUPONNOT C, MOURIAUX F, EYCHENE A et al. Mutation of B-Raf in human choroidal melanoma cells mediates cell proliferation and transformation through the MEK/ERK pathway. J Biol Chem 2003; 278: 42409-42418. https://doi.org/10.1074/jbc.M308709200

[46] ZUIDERVAART W, VAN NIEUWPOORT F, STARK M, DIJKMAN R, PACKER L et al. Activation of the MAPK pathway is a common event in uveal melanomas although it rarely occurs through mutation of BRAF or RAS. Br J Cancer 2005; 92: 2032-2038. https://doi.org/10.1038/sj.bjc.6602598

[47] HENRIQUEZ F, JANSSEN C, KEMP EG, ROBERTS F. The T1799A BRAF mutation is present in iris melanoma. Invest Ophthalmol Vis Sci 2007; 48: 4897-4900. https:/doi. org/10.1167/iovs.07-0440

[48] JANSSEN CS, SIBBETT R, HENRIQUEZ FL, MCKAY IC, KEMP EG et al. The T1799A point mutation is present in posterior uveal melanoma. Br J Cancer 2008; 99: 1673-1677. https://doi.org/10.1038/sj.bjc.6604731 
[49] MALAPONTE G, LIBRA M, GANGEMI P, BEVELACQUA $\mathrm{V}$, MANGANO $\mathrm{K}$ et al. Detection of BRAF gene mutation in primary choroidal melanoma tissue. Cancer Biol Ther 2006; 5: 225-227. https://doi.org/10.4161/cbt.5.2.2429

[50] MAR VJ, WONG SQ, LI J, SCOLYER RA, MCLEAN C et al. BRAF/NRAS wild-type melanomas have a high mutation load correlating with histologic and molecular signatures of UV damage. Clin Cancer Res 2013; 19: 4589-4598. https:// doi.org/10.1158/1078-0432.CCR-13-0398

[51] HACKER E, OLSEN CM, KVASKOFF M, PANDEYA N, YEO A et al. Histologic and Phenotypic Factors and MC1R Status Associated with BRAF(V600E), BRAF(V600K), and NRAS Mutations in a Community-Based Sample of $414 \mathrm{Cu}-$ taneous Melanomas. J Invest Dermatol 2016; 136: 829-837. https://doi.org/10.1016/j.jid.2015.12.035

[52] PLATZ A, EGYHAZI S, RINGBORG U, HANSSON J. Human cutaneous melanoma; a review of NRAS and BRAF mutation frequencies in relation to histogenetic subclass and body site. Mol Oncol 2008; 1: 395-405. https://doi. org/10.1016/j.molonc.2007.12.003

[53] COHEN Y, ROSENBAUM E, BEGUM S, GOLDENBERG D, ESCHE C et al. Exon 15 BRAF mutations are uncommon in melanomas arising in nonsun-exposed sites. Mol Oncol 2008; 1: 395-405. https://doi.org/10.1016/j.molonc.2007.12.003

[54] EDWARDS RH, WARD MR, WU H, MEDINA CA, BROSE MS et al. Absence of BRAF mutations in UV-protected mucosal melanomas. J Med Genet 2004; 41: 270-272. https:// doi.org/10.1136/jmg.2003.016667

[55] ONKEN MD, WORLEY LA, LONG MD, DUAN S, COUNCIL ML et al. Oncogenic mutations in GNAQ occur early in uveal melanoma. Invest Ophthalmol Vis Sci 2008; 49: 52305234. https://doi.org/10.1167/iovs.08-2145

[56] POLLOCK PM, HARPER UL, HANSEN KS, YUDT LM, STARK $M$ et al. High frequency of BRAF mutations in nevi. Nat Genet 2003; 33: 19-20. https://doi.org/10.1038/ng1054

[57] HILL VK, GARTNER JJ, SAMUELS Y, GOLDSTEIN AM. The genetics of melanoma: recent advances. Annu Rev Genomics Hum Genet 2013; 14: 257-279. https://doi. org/10.1146/annurev-genom-091212-153429

[58] JOHNSON DB, PUZANOV I. Treatment of NRAS-mutant melanoma. Curr Treat Options Oncol 2015; 16: 15. https:// doi.org/10.1007/s11864-015-0330-Z

[59] KELLEHER FC, MCARTHUR GA. Targeting NRAS in melanoma. Cancer J 2012; 18: 132-136. https://doi.org/10.1097/ PPO.0b013e31824ba4df

[60] VAN ELSAS A, ZERP SF, VAN DER FLIER S, KRUSE KM, AARNOUDSE C et al. Relevance of ultraviolet-induced Nras oncogene point mutations in development of primary human cutaneous melanoma. Am J Pathol 1996; 149: 883-893.

[61] DEMUNTER A, STAS M, DEGREEF H, DE WOLFPEETERS C, VAN DEN OORD JJ. Analysis of N- and Kras mutations in the distinctive tumor progression phases of melanoma. J Invest Dermatol 2001; 117: 1483-1489. https:// doi.org/10.1046/j.0022-202x.2001.01601.x

[62] SHAIN AH, YEH I, KOVALYSHYN I, SRIHARAN A, TALEVICH E et al. The Genetic Evolution of Melanoma from Precursor Lesions. N Engl J Med 2015; 373: 1926-1936. https://doi.org/10.1056/NEJMoa1502583
[63] PFEIFER GP, BESARATINIA A. Mutational spectra of human cancer. Hum Genet 2009; 125: 493-506. https://doi. org/10.1007/s00439-009-0657-2

[64] SOUSSI T. p53 alterations in human cancer: more questions than answers. Oncogene 2007; 26: 2145-2156. https://doi. org/10.1038/sj.onc. 1210280

[65] ZIEGLER A, JONASON AS, LEFFELL DJ, SIMON JA, SHARMA HW et al. Sunburn and p53 in the onset of skin cancer. Nature 1994; 372: 773-776. https://doi. org/10.1038/372773a0

[66] DUMAZ N, STARY A, SOUSSI T, DAYA-GROSJEAN L, SARASIN A. Can we predict solar ultraviolet radiation as the causal event in human tumours by analysing the mutation spectra of the p53 gene? Mutat Res 1994; 307: 375-386. https://doi.org/10.1016/0027-5107(94)90311-5

[67] OLIVIER M, HUSSAIN SP, CARON DE FROMENTEL C, HAINAUT P, HARRIS CC. TP53 mutation spectra and load: a tool for generating hypotheses on the etiology of cancer. IARC Sci Publ 2004; 157: 247-270.

[68] BRANTLEY MA, JR., HARBOUR JW. Deregulation of the $\mathrm{Rb}$ and $\mathrm{p} 53$ pathways in uveal melanoma. Am J Pathol 2000; 157: 1795-1801. https://doi.org/10.1016/s00029440(10)64817-1

[69] CREE IA. Cell cycle and melanoma--two different tumours from the same cell type. J Pathol 2000; 191: 112-114. https:// doi.org/10.1002/(SICI)1096-9896(200006)191:2<112::AIDPATH592>3.0.CO;2-N

[70] SUN Y, TRAN BN, WORLEY LA, DELSTON RB, HARBOUR JW. Functional analysis of the p53 pathway in response to ionizing radiation in uveal melanoma. Invest Ophthalmol Vis Sci 2005; 46: 1561-1564. https://doi.org/10.1167/ iovs.04-1362

[71] MULLER PA, VOUSDEN KH. p53 mutations in cancer. Nat Cell Biol 2013; 15: 2-8. https://doi.org/10.1038/ncb2641

[72] ZERP SF, VAN ELSAS A, PELTENBURG LT, SCHRIER PI. p53 mutations in human cutaneous melanoma correlate with sun exposure but are not always involved in melanomagenesis. Br J Cancer 1999; 79: 921-926. https://doi.org/10.1038/ sj.bjc. 6690147

[73] VIROS A, SANCHEZ-LAORDEN B, PEDERSEN M, FURNEY SJ, RAE J et al. Ultraviolet radiation accelerates BRAFdriven melanomagenesis by targeting TP53. Nature 2014; 511: 478-482. https://doi.org/10.1038/nature13298

[74] CHOI YS, FISHER DE. UV and melanoma: the TP53 link. Cell Res 2014; 24: 1157-1158. https://doi.org/10.1038/ cr.2014.95

[75] VINAGRE J, ALMEIDA A, POPULO H, BATISTA R, LYRA J et al. Frequency of TERT promoter mutations in human cancers. Nat Commun 2013; 4: 2185. https://doi.org/10.1038/ ncomms 3185

[76] HORN S, FIGL A, RACHAKONDA PS, FISCHER C, SUCKER A et al. TERT promoter mutations in familial and sporadic melanoma. Science 2013; 339: 959-961. https://doi. org/10.1126/science.1230062

[77] HUANG FW, HODIS E, XU MJ, KRYUKOV GV, CHIN L et al. Highly recurrent TERT promoter mutations in human melanoma. Science 2013; 339: 957-959. https://doi. org/10.1126/science.1229259 
[78] DONO M, ANGELINI G, CECCONI M, AMARO A, ESPOSITO AI et al. Mutation frequencies of GNAQ, GNA11, BAP1, SF3B1, EIF1AX and TERT in uveal melanoma: detection of an activating mutation in the TERT gene promoter in a single case of uveal melanoma. Br J Cancer 2014; 110: 1058-1065. https://doi.org/10.1038/bjc.2013.804

[79] KOOPMANS AE, OBER K, DUBBINK HJ, PARIDAENS D, NAUS NC et al. Prevalence and implications of TERT promoter mutation in uveal and conjunctival melanoma and in benign and premalignant conjunctival melanocytic lesions. Invest Ophthalmol Vis Sci 2014; 55: 6024-6030. https://doi. org/10.1167/iovs.14-14901

[80] GRIEWANK KG, MURALI R, SCHILLING B, SCHOLZ S, SUCKER A et al. TERT promoter mutations in ocular melanoma distinguish between conjunctival and uveal tumours. Br J Cancer 2013; 109: 497-501. https://doi.org/10.1038/ bjc.2013.312

[81] DING L, KIM M, KANCHI KL, DEES ND, LU C et al. Clonal architectures and driver mutations in metastatic melanomas. PLoS One 2014; 9: e111153. https://doi.org/10.1371/journal. pone. 0111153

[82] SINGH AD, RENNIE IG, SEREGARD S, GIBLIN M, MCKENZIE J. Sunlight exposure and pathogenesis of uveal melanoma. Surv Ophthalmol 2004; 49: 419-428. https://doi. org/10.1016/j.survophthal.2004.04.009

[83] ELIASON MJ, HANSEN CB, HART M, PORTER-GILL P, CHEN W et al. Multiple primary melanomas in a CDKN2A mutation carrier exposed to ionizing radiation. Arch Dermatol 2007; 143: 1409-1412. https://doi.org/10.1001/archderm.143.11.1409

[84] KANNENGIESSER C, AVRIL MF, SPATZ A, LAUD K, LENOIR GM et al. CDKN2A as a uveal and cutaneous melanoma susceptibility gene. Genes Chromosomes Cancer 2003; 38: 265-268. https://doi.org/10.1002/gcc.10286
[85] HODIS E, WATSON IR, KRYUKOV GV, AROLD ST, IMIELINSKI $\mathrm{M}$ et al. A landscape of driver mutations in melanoma. Cell 2012; 150: 251-263. https://doi.org/10.1016/j. cell.2012.06.024

[86] WILLIAMS M, OUHTIT A. Towards a Better Understanding of the Molecular Mechanisms Involved in Sunlight-Induced Melanoma. J Biomed Biotechnol 2005; 2005: 57-61. https://doi.org/10.1155/JBB.2005.57

[87] PERIS K, CHIMENTI S, FARGNOLI MC, VALERI P, KERL $\mathrm{H}$ et al. UV fingerprint CDKN2a but no p14ARF mutations in sporadic melanomas. J Invest Dermatol 1999; 112: 825826. https://doi.org/10.1046/j.1523-1747.1999.00575.x

[88] AHMAD I, GUROJI P, DEBROT AH, MANAPRAGADA PP, KATIYAR SK et al. Loss of INK4a/Arf gene enhances ultraviolet radiation induced cutaneous tumor development. Exp Dermatol 2017; 26: 1018-1025. https://doi.org/10.1111/ exd.13356

[89] MING M, FENG L, SHEA CR, SOLTANI K, ZHAO B et al. PTEN positively regulates UVB-induced DNA damage repair. Cancer Res 2011; 71: 5287-5295. https://doi. org/10.1158/0008-5472.CAN-10-4614

[90] SHTIVELMAN E, DAVIES MQ, HWU P, YANG J, LOTEM $\mathrm{M}$ et al. Pathways and therapeutic targets in melanoma. Oncotarget 2014; 5: 1701-1752. https://doi.org/10.18632/oncotarget.1892

[91] PEREZ-ALEA M, VIVANCOS A, CARATU G, MATITO J, FERRER B et al. Genetic profile of GNAQ-mutated blue melanocytic neoplasms reveals mutations in genes linked to genomic instability and the PI3K pathway. Oncotarget 2016; 7: 28086-28095. https://doi.org/10.18632/oncotarget.8578 